\title{
A BUSCA POR CUIDADO EMPREENDIDA POR USUÁRIO COM DIABETES MELLITUS - UM CONVITE À REFLEXÃO SOBRE A INTEGRALIDADE EM SAÚDE ${ }^{1}$
}

\author{
Geovana Hagata de Lima Souza Thaines², Roseney Bellato³, Ana Paula Silva de Faria4, Laura Filomena \\ Santos de Araújo
}

\begin{abstract}
${ }^{1}$ Parte integrante do Sub-Projeto II no âmbito da Pesquisa “Os desafios e perspectivas do SUS na atenção à saúde em municípios da área de abrangência da BR 163 no Estado de Mato Grosso" financiada pelo Conselho Nacional de Desenvolvimento Científico e Tecnológico (CNPq).

${ }^{2}$ Aluna do Curso de Graduação em Enfermagem da Faculdade de Enfermagem da Universidade Federal de Mato Grosso (FAEN/UFMT). Bolsista de Iniciação Científica 2006-2007/CNPq. Mato Grosso, Brasil. E-mail: geohagata@gmail.com

${ }^{3}$ Doutora em enfermagem. Docente da FAEN/UFMT. Mato Grosso, Brasil. E-mail: roseney@terra.com.br

${ }^{4}$ Mestre em Enfermagem. Enfermeira da Secretaria Estadual de Saúde do Mato Grosso. Docente do Curso de Graduação em Enfermagem do Cetro Universitário Cândido Rondon. Mato Grosso, Brasil. E-mail: apaula.rn@uol.com.br

${ }^{5}$ Doutora em enfermagem. Docente da FAEN/UFMT. Mato Grosso, Brasil. E-mail: laurafil1@yahoo.com.br
\end{abstract}

\begin{abstract}
RESUMO: Estudo de caso que objetivou compreender a trajetória empreendida por um usuário com Diabetes mellitus, proveniente do município de Sorriso-MT, ao buscar atendimento às suas necessidades de saúde, bem como analisar a lógica que o direcionou nessa busca, tendo por perspectiva o princípio da integralidade da atenção à saúde. A coleta de dados foi realizada pela entrevista em profundidade e nos permitiu desenhar o Itinerário Terapêutico empreendido pelo usuário na sua busca por cuidados. Dos dados emergiram três agrupamentos de sentido, delineados como a evolução da própria experiência de adoecimento do usuário e a busca por cuidados, a sua percepção do que seja cuidado e a negação da sua condição crônica. Compreender essa vivência pessoal e subjetiva do adoecimento nos possibilita entender que a integralidade da atenção à saúde depende de práticas profissionais que considerem o modo como as pessoas reconstroem suas vidas frente à condição crônica por Diabetes mellitus.
\end{abstract}

DESCRITORES: Enfermagem. Diabetes mellitus. Atenção à saúde.

\section{THE SEARCH FOR CARE UNDERTAKEN BY A USER WITH DIABETES MELLITUS - AN INVITATION FOR REFLECTION ABOUT COMPREHENSIVENESS IN HEALTH CARE}

\begin{abstract}
This is a case study aimed at understanding better the trajectory undertaken by a user with Diabetes mellitus from the municipality of Sorriso-MT, Brazil in seeking care for his/her health care needs, as well as analyzing the logic that guided the search, given the perspective of the principle of integrality in health care. Data was collected through an in-depth interview and allowed us to draw the Therapeutic Itinerary undertaken by the user in their search for care. From the data three sense groups emerged, outlined as the evolution of the user's illness experience and search for care, their perception of what it is to be cared for, and the denial of their chronic condition. Understanding this personal and subjective illness experience allows us to better understand that the whole of health care depends on professional practices which consider how people rebuild their lives in facing the chronic condition of Diabetes mellitus.

DESCRIPTORS: Nursing. Diabetes mellitus. Health care.
\end{abstract}

\section{LA BÚSQUEDA POR CUIDADO EMPRENDIDA POR EL USUARIO CON DIABETES MELLITUS - UNA INVITACIÓN PARA LA REFLEXIÓN SOBRE LA INTEGRALIDAD EN SALUD}

\begin{abstract}
RESUMEN: Estudio de caso cuyo objetivo fue comprender la trayectoria emprendida por un usuario con Diabetes mellitus en el municipio de Sorriso-MT, al buscar atención para sus necesidades de salud, además de analizar la lógica que lo guía en esa búsqueda, teniendo como perspectiva el principio de la integralidad de la atención a la salud. La recolección de los datos se realizó mediante entrevista en profundidad, la cual nos permitió delinear el Itinerario Terapéutico realizado por el usuario en su búsqueda por atención. De los datos surgieron tres grupos de sentido, con los que se describe la evolución de la experiencia del usuario ante la enfermedad y la búsqueda de atención, su percepción de lo que es el cuidado y la negación de su condición crónica. Comprender esa experiencia personal y subjetiva de la enfermedad nos permite entender que la integralidad de la atención a la salud depende de prácticas profesionales que tengan en cuenta el modo cómo las personas reconstruyen sus vidas ante la condición crónica de la Diabetes mellitus.
\end{abstract}

DESCRIPTORES: Enfermería. Diabetes mellitus. Atención a la salud. 


\section{INTRODUÇÃO}

Este estudo teve como foco a compreensão da experiência de adoecimento e busca por cuidado empreendido por uma pessoa com Diabetes Mellitus (DM), as repercussões que essa condição crônica tem em sua vida, bem como o modo como os serviços de saúde disponibilizam o cuidado às suas necessidades. A abordagem desse tema reveste-se de importância visto a implicação que esse agravo, como uma síndrome de etiologia múltipla, acarreta. Dentre as possíveis complicações a disfunção e falência de vários órgãos, especialmente rins, olhos, nervos, coração e vasos sanguíneos são as mais comuns. Também seu perfil epidemiológico justifica a discussão aqui empreendida, pois, segundo a Organização Pan-Americana de Saúde, cerca de 177 milhões de pessoas sofrem desse agravo, número que deverá duplicar até $2030 .^{1-2}$ Também no Brasil os dados são preocupantes, pois, no ano de 2005, foram registrados 40.317 óbitos por complicações decorrentes do DM em todo o país, com 2.255 desses óbitos ocorridos na Região Centro Oeste. ${ }^{3}$

Frente à gravidade da situação atual e perspectivas de piora em futuro próximo, esse agravo tornou-se um importante problema de saúde pública, levando o Sistema Único de Saúde (SUS) a desenvolver ações que possam minimizá-lo. Como Política de Saúde direcionadora dessas ações, o Ministério da Saúde, em 2000, implantou o Plano de Reorganização da Atenção à Hipertensão Arterial e ao DM, visando investir na atualização de profissionais da rede básica, proporcionando a vinculação da pessoa com diabetes e/ou hipertensão arterial às unidades de saúde para tratamento e acompanhamento, buscando compor um atendimento resolutivo e de qualidade. ${ }^{1}$

Faz-se necessário considerar também, que o DM é classificado como uma condição crônica, visto ser persistente na vida da pessoa e requer atenção especial e constante, ${ }^{4}$ bem como por gerar outros agravos que podem ser temporários ou, na maioria das vezes, prolongados ou permanentes. Entendemos que os agravos que assim se caracterizem, embora raramente curáveis, são passíveis de gerenciamento pelos serviços de saúde, pessoa doente e por sua família. No entanto, por demandar cuidado continuado e prolongado, há necessidade de que os serviços de saúde se organizem para oferecê-lo de maneira integral, não se limitando a possibilitar o acesso da pessoa aos serviços, particularmente na atenção básica, mas que neles encontre práticas profissionais resolutivas frente às necessidades requeridas, tanto por parte da própria pessoa doente quanto de sua família. ${ }^{5}$

Neste sentido, destaca-se a importância da integralidade da atenção como princípio norteador no atendimento à pessoa em condição crônica por DM, cujas necessidades de saúde não prescindem do cuidado em suas fases de agudização, embora tragam outras demandas que precisam ser também consideradas. Essa pessoa necessita, além do tratamento medicamentoso e da mudança de hábitos alimentares, de apoio e orientação, de modo que possa desenvolver a autonomia para o cuidado, tornando mais fácil sua convivência com a condição que, não sendo transitória, acarreta uma série de mudanças em suas vidas, tanto em relação à sua rotina, aos seus hábitos, bem como a aceitação da própria condição. ${ }^{6}$

Mas, para que possamos empreender práticas mais cuidativas que se pautem na integralidade da atenção, é necessário compreender as mudanças que o DM imprime a vida da pessoa e sua família, bem como o modo como se dão as demandas por busca de cuidado em saúde. Assim, a perspectiva da integralidade nos convida a repensar a maneira como estão organizadas as práticas de cuidado e de gestão destinadas à pessoa que vivencia essa condição crônica, de modo a responder as suas necessidades de saúde que se expressam, de maneira intensa, no seu viver cotidiano e aí precisam ser gerenciadas.

Tendo por base as considerações feitas quanto à condição crônica e a necessidade de práticas profissionais mais integrativas, consideramos importante compreender a experiência de adoecimento e busca por cuidado empreendido por uma pessoa diabética, trazendo em destaque a trajetória por ela percorrida nessa busca e a lógica que a direcionou. Para possibilitar essa compreensão desenhamos os diversos percursos desta trajetória compondo, assim, o Itinerário Terapêutico (IT) desta pessoa. O IT é por nós considerado como os percursos empreendidos pela pessoa doente e sua família na busca por resolver suas necessidades de saúde, bem como a lógica própria que o direciona, tecida nas múltiplas redes formais e informais, de apoio e de pertença, dentre outras, que possam lhes dar certa sustentabilidade na sua experiência de adoecimento. Comporta, também, como os serviços de saúde disponibilizam a produção de cuidados, segundo sua própria lógica, e a forma como acolhem essa pessoa e sua família atendendo, em certa medida e de certo modo, suas necessidades. ${ }^{7}$ 
Desta forma, é objetivo deste estudo compreender a trajetória empreendida por uma pessoa com DM proveniente do município de Sorriso-MT, ao buscar atendimento às suas necessidades de saúde, bem como analisar a lógica que o direcionou nessa busca, tendo por perspectiva o princípio da Integralidade da atenção à saúde.

\section{METODOLOGIA}

Este estudo desenha-se como Estudo de Caso e busca oferecer um olhar compreensivo para a experiência da condição crônica por DM e a busca por cuidados empreendida pelo Sr. Miguel $^{*}$, procedente do município de Sorriso, no interior de Mato Grosso, e que esteve internado na Clínica Cirúrgica de um hospital público de Cuiabá-MT para amputação de hálux direito por necrose, tendo ainda por agravos a sua saúde a hipertensão arterial e a insuficiência renal crônica a esclarecer. Por essas complicações apresentadas em decorrência do DM o Sr. Miguel se enquadrou nos critérios de escolha dos sujeitos da pesquisa, pelo fato de se constituir em um evento-sentinela, ou seja, apresentar sério agravo à saúde que poderia ter sido evitado através de uma assistência eficaz no início do seu aparecimento. ${ }^{8}$

Para apreensão dos dados foi utilizada a abordagem metodológica da História de Vida Focal, empreendida através da entrevista em profundidade, sendo que a pessoa é convidada a falar sobre sua experiência de forma livre e, a partir do estabelecimento do vínculo pesquisador-entrevistado, é que se dá o aprofundamento dos temas importantes para a pesquisa. Assim, embora se parta inicialmente de uma questão norteadora, é a condução da própria entrevista que fornece os elementos essenciais para o aprofundamento das narrativas. Neste contexto, a escuta atenta é essencial, bem como a observação do contexto da fala. ${ }^{9}$ Com base nessas prerrogativas tivemos a seguinte questão norteadora da entrevista: conteme como se deu a busca por atendimento ao seu problema de saúde desde o seu aparecimento até a sua internação neste hospital.

Os encontros da entrevista foram realizados entre os dias 22/01 e 22/02/2007 e as narrativas do Sr. Miguel proporcionaram a apreensão da lógica que o direcionou em sua busca por cuidados, assim como permitiu o mapeamento dos serviços de saúde nos quais foi atendido, compondo a trajetória por ele empreendida. Para melhor com- preender a realidade vivida pelo $\mathrm{Sr}$. Miguel fomos até o município onde reside e aí pudemos conhecer sua casa, assim como os serviços de saúde por ele utilizados, bem como pudemos observar algumas práticas profissionais de cuidado e de gestão. No entanto, neste estudo, nos centramos nos dados obtidos pelas narrativas do Sr. Miguel sobre a sua experiência de adoecimento e busca por cuidados, sendo que essa observação nos possibilitou apreender a dimensão do contexto da experiência. Essa segunda fase de trabalho de campo da pesquisa foi realizada entre os dias 25 e 27/07/2007.

Os dados de entrevista compuseram o corpus de análise que, submetido à leitura exaustiva, evidenciou o IT do Sr. Miguel, comportando os percursos por ele empreendidos e os sentidos que atribui à sua vivência da condição crônica por DM. Na construção do IT cada percurso é apresentado por uma seta, cuja direção especifica o sentido do movimento empreendido por ele entre os serviços de saúde, sua rede de apoio e, em alguns casos, a referência e contra-referência feita por um serviço de saúde a outro. A numeração presente em cada uma das setas indica a ordem temporal em que as buscas aconteceram, de modo crescente. Da leitura cuidadosa dos dados de entrevista e após a construção do desenho do IT, organizamos a análise através de três agrupamentos de sentido dessa experiência a saber - Contando a experiência de adoecimento do Sr Miguel; O cuidado na visão do Sr Miguel e Negação da condição crônica.

Todos os procedimentos éticos previstos na Resolução No 196/96 do Conselho Nacional de Saúde foram respeitados integralmente, com aprovação do projeto de pesquisa ao qual este estudo se vincula pelo Comitê de Ética em Pesquisa com Seres Humanos do Hospital Universitário Julio Muller, sob o No 235/CEP-HUJM/2005. A realização da entrevista foi precedida pela assinatura do Termo de Consentimento Livre e Esclarecido pelo Sr. Miguel.

\section{RESULTADOS E DISCUSSÃO}

\section{Contando a experiência de adoecimento do Sr. Miguel}

O Sr. Miguel descobriu ser diabético há quinze anos quando ainda residia no Estado do Maranhão, onde ainda moram as suas filhas, tendo vindo para Mato Grosso a convite do irmão, que hoje reside em Cuiabá. Atualmente mora

* Como garantia de anonimato empregamos um nome fictício ao sujeito do estudo e demais pessoas citadas. 
sozinho, no município de Sorriso, no interior do Estado, numa casa, cujo terreno têm outras quatro casas e, em uma delas, mora seu primo também diabético. A casa é de madeira, com dois cômodos que são separados por uma cortina, sendo um ambiente escuro e sem janelas. Os cômodos são muito pequenos e, assim, tudo é muito próximo. Os banheiros são externos, bem como o tanque para lavar roupas, sendo que essa área é comum aos quatro outros moradores do local. A porta da casa é fechada por uma corrente e um grande cadeado. $\mathrm{O}$ bairro onde reside é todo asfaltado e possui ruas que terminam em mata fechada que cerca a cidade nesse local.

A Figura 1 mostra o trajeto empreendido pelo Sr. Miguel em busca de cuidado e de resolutividade para as suas necessidades de saúde, desde sua chegada em Sorriso até sua vinda para Cuiabá, por conta própria, em busca de resolutividade para seu problema renal em 2006. Dentre os diversos percursos empreendidos, daremos destaque a alguns deles que se mostram mais representativos da buscas por ele empreendidas e das respostas obtidas junto aos serviços de saúde.
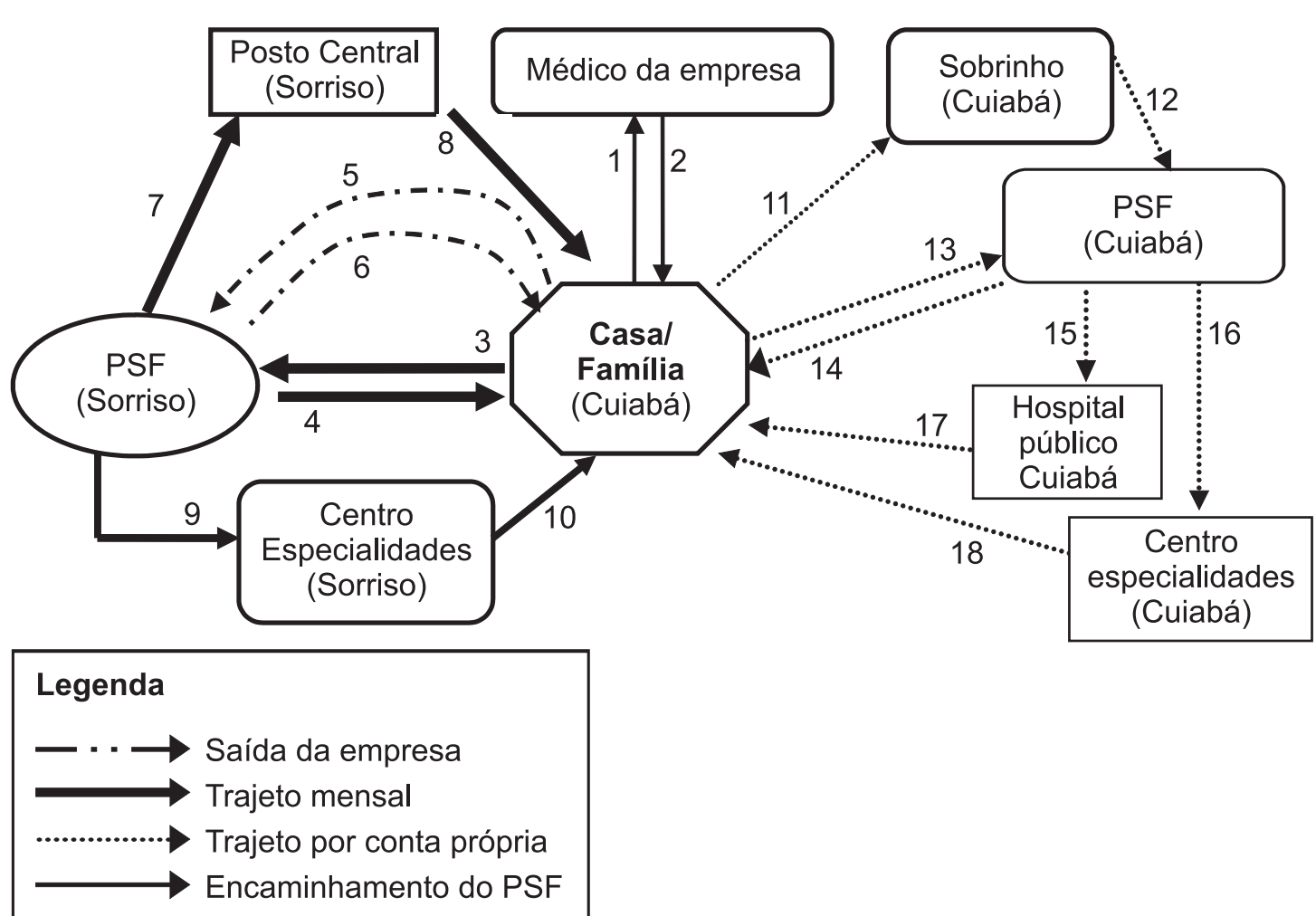

Figura 1 - Itinerário terapêutico do Sr. Miguel, de sua busca inicial por cuidado em Sorriso até sua vinda para Cuiabá-MT

Inicialmente o Sr. Miguel consultava com o médico da empresa onde trabalhava (setas 1 e 2, Figura 1), ainda que fosse cadastrado no Programa Saúde da Família (PSF) do seu bairro, sendo que as medicações prescritas pelo médico eram retiradas nesta unidade de saúde. Com sua saída da empresa passou a se consultar apenas com o médico do PSF. Este PSF é o que atende maior contingente populacional e um dos mais antigos do município de Sorriso. Em uma mesma estrutura física funcionam duas unidades de saúde da família e abrange tanto a população do bairro em que reside quanto do bairro vizinho. O espaço físico é compartilhado pelas duas unidades, não havendo uma divisão física entre elas e a delimitação de território para atendimento é realizada através do emprego de cartões de identificação diferenciados em duas cores.

Faz parte das práticas de cuidado à pessoa com DM desenvolvida pelo PSF em que o Sr. Miguel é atendido, tanto a consulta médica como a reunião do grupo de hipertensos e diabéticos. Essas atividades são agendadas e comunicadas, mensalmente, 
aos usuários pela agente comunitária de saúde, sendo que, cada semana, é atendida uma micro-área dessa unidade. Primeiramente, o usuário passa pela triagem de enfermagem, depois acontece a reunião do grupo de hipertensos e diabéticos, direcionada pelo médico ou enfermeiro da unidade. Após a reunião é realizada a consulta médica.

Nesse PSF, o Sr. Miguel retira as medicações de uso oral para o controle do DM sendo que a insulina é buscada por ele na unidade de saúde localizada nas proximidades do Hospital Público municipal, na área central da cidade, que a população denomina de Posto Central. Aí funcionam, em uma mesma estrutura física, três unidades de saúde da família e dista, aproximadamente, cinco quilômetros da residência do Sr. Miguel. [...] Em pé é longe. Fica lá no centro. [...] É, eu pegava a bicicleta e eu ia lá. [...] Eu ia lá receber remédios lá. [...] Que era a insulina, pegá o aparelho para aplicar a insulina que eu ia pegar lá. Só isso que eu fazia lá. Pegar lá (e1).

Pudemos observar que esse Posto centraliza a distribuição de insulina para todo o município, o que diverge da proposta do Plano de Reorganização da Atenção a Hipertensão Arterial e DM, ${ }^{1}$ que prevê a distribuição de toda medicação na própria unidade básica em que o Sr. Miguel está cadastrado. Ele deve retirar no Posto Central, mensalmente, a insulina de que necessita. Para tanto, precisa se deslocar de bicicleta de sua casa até essa unidade, visto que não há transporte coletivo que faça o trajeto. Para chegar à área central da cidade e à unidade onde essa medicação é distribuída, é necessário atravessar as duas pistas da Rodovia Federal BR 163, que apresenta intenso tráfego de grandes caminhões graneleiros. Mas, como pudemos observar no seu cartão de controle de insulina na sua unidade de referência, ele não tem retirado esta medicação desde dezembro de 2006. Indagamo-nos sobre o que poderá ter contribuído para isto.

Durante nossa visita à unidade de saúde pudemos observar que na ficha de controle interna da unidade e no prontuário do Sr. Miguel não há relato sobre as suas faltas para retirar a medicação. No período de janeiro a fevereiro deste ano, o mesmo esteve em tratamento em Cuiabá. Mas, e nos meses anteriores? Frente a essa situação identificamos que não há comunicação entre o Posto Central e o PSF no qual é cadastrado, não havendo, também, a busca ativa para investigar o que está levando o usuário a não retirar a insulina mensalmente.

Em período anterior a esse, o Sr Miguel foi encaminhado, pelo PSF de origem, para avaliação de um cardiologista, pois, além das pernas edema- ciadas, havia também uma ferida que não sarava (e1) no seu pé. Nesta consulta, ele solicitou ao médico um exame de leishmaniose (e1), e este negou seu pedido, o que contribuiu para que, frente ao fato de perceber que suas necessidades de saúde não estavam sendo ouvidas e atendidas, empreendesse nova busca por serviços de saúde. Essa busca foi mediada por sua família, mais especificamente por um sobrinho que trabalha em um PSF de Cuiabá, conforme demonstra a seta 11 da Figura 1. Nesta nova busca, o Sr. Miguel foi cadastrado no PSF do bairro em que sua família reside em Cuiabá, para proceder a retirada de medicações para diabetes e tentar ser encaminhado para outros níveis de atendimento, como a um Hospital Público de Cuiabá e o Centro de Especialidades do Município (setas 15 e 16 da Figura 1).

Esta primeira vinda do Sr. Miguel à Cuiabá foi resultante das necessidades de saúde não atendidas em seu município pelos serviços de saúde procurados. O médico do Centro de Especialidades de Sorriso, mesmo sabendo ser ele diabético, não o encaminhou para nenhum serviço de referência, seja para diagnóstico ou tratamento, e não valorizou o fato dele apresentar as pernas edemaciadas, bem como uma ferida de longo curso e de difícil cicatrização no pé direito. O médico também não ouviu o que o Sr. Miguel tinha a dizer, pois o mesmo, conhecendo o seu próprio corpo e sua condição crônica, intuía que seu problema não era cardíaco: Eu digo que não, porque as minhas pernas estavam inchando. Eles estavam falando que era coração. Mas não era coração. Era problema nos rins (e1).

É interessante ressaltar que o controle da doença exercido pelos profissionais de saúde está presente "como toda forma de, numericamente, identificar a pessoa com Diabetes mellitus dentro da unidade de saúde, bem como nas demais instâncias elaboradoras ou executoras de políticas de atenção a esse agravo, tanto no nível municipal, como estadual e federal. A noção de biopoder nos parece útil para analisar as formas de controle exercidas nas unidades de saúde, sendo que, no caso das pessoas com Diabetes mellitus ele se faz presente de modo positivo para controlar suas vidas em nome de um melhor nível de saúde"10:101 Esse poder sobre a vida é empregado para controlar os corpos individuais e a população, ou seja, como um mecanismo de controle e coerção "[...] para a produtividade e saúde de corpos humanos e populações $[. . .]^{\prime \prime}$, baseando-se em uma visão destes como "[...] recursos e objetos passíveis de serem administrados". 11:149 
Percebemos que esse biopoder se põe em movimento no modo de configurar as práticas de atenção a pessoa com diabetes e/ou hipertensão arterial, pretendendo um controle insidioso sobre cada "caso", o Sr. Miguel dentre tantos, que deve ter sua vida administrada, em sua forma de adoecer e se cuidar, segundo os padrões de saúde, assim como um controle sobre o conjunto das pessoas com esses agravos. Para tanto, se arma de dispositivos que tendem a normalizar a diversidade que é a vida em movimento e determina, de forma muito rígida, as possibilidades de oferta de cuidados. Esta oferta, no modo como é organizada, se mostra pouco resolutiva para o usuário, permitindo poucas possibilidades de responder às suas necessidades em saúde.
A centralização da distribuição da insulina em um único serviço de saúde, embora se mostre uma estratégia aparentemente eficiente em termos administrativos, ou seja, possibilita um maior domínio desse insumo empregado no controle da doença, é contrário às necessidades das pessoas diabéticas que precisam se deslocar por grandes distâncias para consegui-lo. A racionalidade presente é, portanto, muito mais de controle dos meios possíveis de se produzir o cuidado do que propriamente da resolução das necessidades com o uso facilitado e acessível desses meios àquelas pessoas que deles precisam.

A Figura 2 evidencia o percurso empreendido pelo Sr. Miguel, desde que foi encaminhado pela Central de Regulação para avaliação de sua função renal, em Cuiabá, até sua amputação, do hálux direito, em janeiro de 2007.

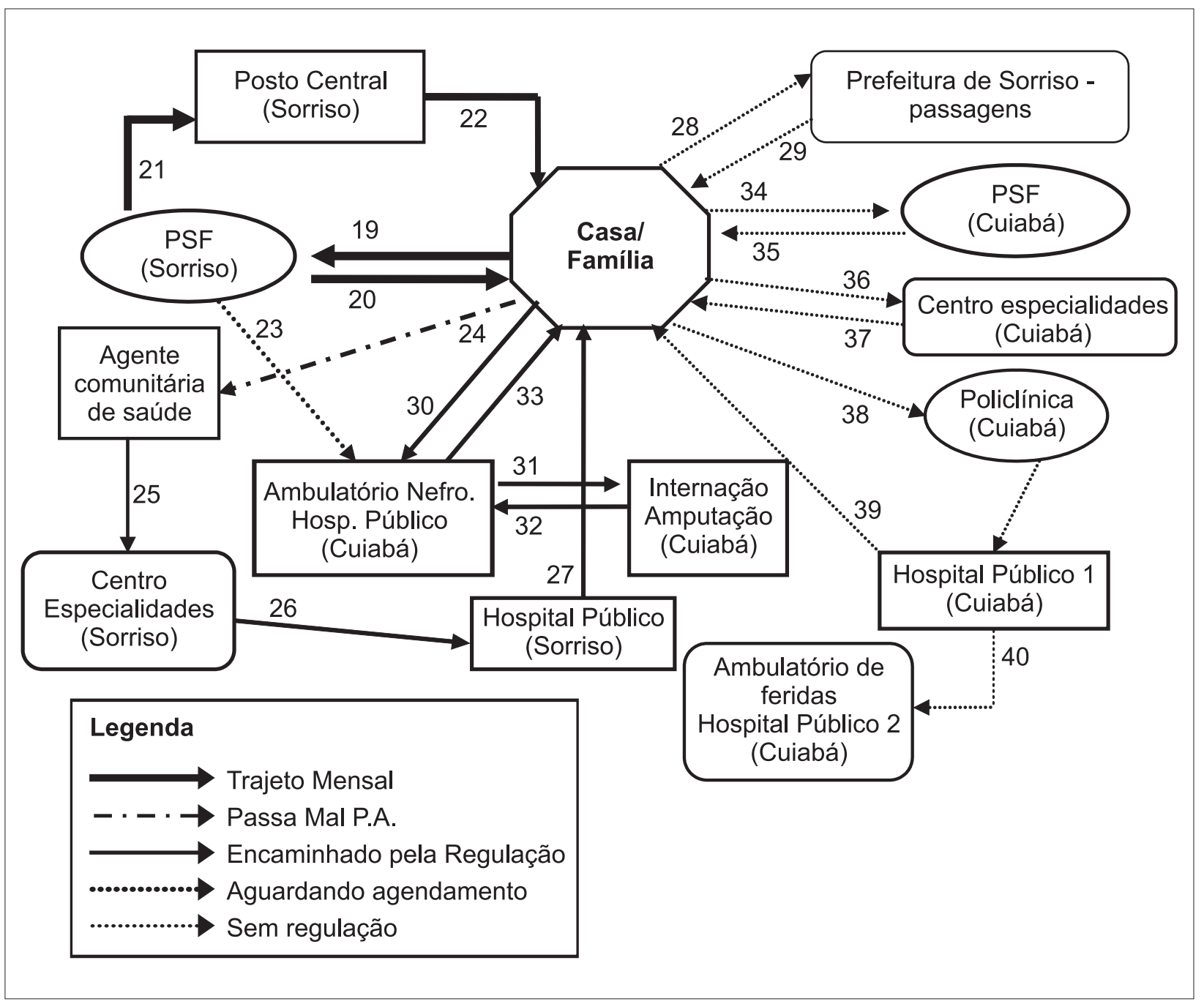

Figura 2 - Itinerário terapêutico do Sr. Miguel, de sua vinda para Cuiabá-MT até a amputação do hálux direito 
A trajetória que culminou com a vinda do $\mathrm{Sr}$. Miguel para Cuiabá teve início no final de 2006, quando, em uma consulta de rotina, o médico do PSF de seu bairro no município de Sorriso o encaminhou para avaliação com o Nefrologista, agendada no ambulatório de nefrologia de um hospital público em Cuiabá, em janeiro de 2007 (seta 23, Figura 2). Enquanto aguardava esse agendamento pela Central de Regulação ele sentiu-se mal e procurou a Agente Comunitária de Saúde do PSF do seu bairro, que o levou para o Centro de Referência para Especialidades Médicas e, aí, foi referenciado para o hospital público de Sorriso (seta 25, Figura 2), pelo fato de suas pernas estarem muito edemaciadas.

Aí quando eu cheguei aqui eu nem urinava. Não urinava não, viu? Aí meu estômago também, que era estômago cheio, não podia comer, não podia beber. Era isso aí. Cheguei inchado. Tava inchado o meu corpo todo. [...] A insulina que a gente não pode tomar demais. Pois se tomar demais dá agonia na gente, e baixa a pressão, e a diabetes e a gente fica assim sentado. [...] Quando ela tá atacando a gente, a gente fica ruim. [...] Não pode não. Insulina demais não pode tomar, não, que ela dá comoção, da agonia na gente. Ela dá ataque, né? (e1)

Em todo o percurso empreendido pelo $\mathrm{Sr}$. Miguel podemos analisar que a prática médica foi focalizada na doença e nos sinais e sintomas que essa manifestava, embora de forma parcializada, e que este saber médico construído sobre a doença não considerou o saber sobre seu próprio corpo e sobre si mesmo como pessoa doente, bem como o fato de atribuir sentido diferenciado aos sinais e sintomas por ele apresentados. Perde-se, assim, a valiosa oportunidade do diálogo como encontro de pessoas e saberes em que há varias possibilidades de ampliar o olhar e identificar as necessidades de saúde que estes apresentam. E podemos afirmar que "[...] está tudo ali, na 'cestinha de necessidades', precisando ser, de alguma forma, escutado e traduzido pela equipe"..$^{12: 116} \mathrm{E}$ ele estava ali, diante do médico, diante de alguém que esperava pudesse solucionar o seu problema de saúde. Mas, apenas estar diante do outro não é suficiente, pois "[...] as necessidades de saúde requerem capacidade de escuta, de respeito à diversidade humana, cultural e de compreensão da saúde e da doença". 13:26

A lógica do profissional, imposta pelo silenciamento do outro, pode dificultar a criação de vínculo com o usuário que espera encontrar no profissional a solução para os seus problemas de saúde. Para a criação do vinculo é necessário, também, que a "confiança no médico seja fruto de um processo de conquista por meio de seu poder de convicção. Sem a confiança, não existe a colaboração do doente, que é essencial para a cura. Esse fator curativo pertence a uma dimensão completamente distinta da ação físico-química dos medicamentos sobre o organismo ou mesmo da intervenção cirúrgica e requer que o médico saiba delimitar seu poder como profissional e adote mais critérios na sua atuação". ${ }^{14: 8}$ Nessa busca por cuidado, porém, aconteceu o inverso, pois o parecer do médico não o convenceu, visto que a sua necessidade de saúde não foi atendida e, muito menos, compreendida em relação ao seu sentir-se mal com o uso da insulina. Essa situação acaba por gerar o desânimo, que o Sr. Miguel expressa como: foi indo, foi indo, até que eu desisti (e1).

Foi movido pelo sentimento de descrença em relação às possibilidades de resolver seu problema de saúde em Sorriso que o Sr. Miguel empreende novas buscas por cuidado, vindo para Cuiabá à procura do apoio da família e do sobrinho que trabalha em um PSF deste município (seta 11, Figura 1) e gerando novas trajetórias em seu já longo itinerário. Chamamos a atenção para o fato de que uma nova busca por cuidado é gerada quando as necessidades de saúde não são atendidas e nem identificadas pelo profissional de saúde, acrescentando novos percursos ao desenho do seu itinerário, empreendido segundo sua lógica própria de cuidado e resolutividade. Entendemos que, se a integralidade da atenção é atributo das boas práticas dos profissionais e que envolve o esforço de compreensão do sofrimento vivido ou antecipado causado pela doença no modo de andar a vida de cada pessoa, esta não deve decorrer automaticamente de protocolos nem da unilateralidade da experiência do profissional. ${ }^{15}$

\section{O cuidado na visão do Sr. Miguel}

Outro aspecto que se mostrou importante na análise dos dados foi a concepção de cuidado que o Sr. Miguel tem, pois esta se centra, principalmente, na consulta médica, na aquisição de medicamentos e tiras para glicosímetro, bem como na realização de exames. O autocuidado é construído em torno da auto-aplicação de insulina, da tomada dos medicamentos prescritos e do comparecimento a consulta medica mensalmente. Vale ressaltar, que aplicar insulina em si mesmo foi uma forma de não ter que ir todos os dias a unidade de saúde e aguardar a disponiilidade dos profissionais para administrar a medicação. Assim, aprender a auto- 
aplicar a insulina se constituiu em um modo do Sr. Miguel solucionar um problema gerado pelo serviço de saúde e seus profissionais.

Eu recebi lá no posto (a insulina). [...] Foi um rapaz, um enfermeiro. É difícil aplicar porque eu não sabia. Aí depois ele me ensinou. Aí ele me ensinou e eu fiquei aplicando por minha conta (e1).

A mesma situação de arranjo do cotidiano em relação à aplicação da insulina se deu em torno do curativo na ferida do seu pé, pois também esse procedimento exigia uma espera na unidade que ele não estava disposto a aceitar.

É, meu curativo [...] Eu to passando uma pomadinha. É para ver se melhora um pouquinho. Graças a Deus eu estou melhor. Foi meu sobrinho que trouxe [essa pomada a que o Sr. Pedro se refere é Neo Nistatin 10.000 UI, creme vaginal]. Só ela mesmo. Passando... Só lavando. Lavando com sabão o pé. Eu to lavando com sabão. Eu pego o remédio lá [na unidade de saúde em Cuiabá] e faço aqui em casa. Aqui eu faço com mais cuidado aqui. Você está me entendendo? Faço duas vezes (e1).

Em suas buscas por cuidado junto às unidades de saúde, nos diferentes níveis de atenção, suas necessidades foram resumidas apenas ao aprendizado da aplicação de insulina e realização de curativo em ferida, sendo que o Sr. Miguel logo aprendeu a executar esses procedimentos, reconhecendo-os como centrais nas praticas profissionais a pessoa com diabético. Em suas narrativas ele não menciona outras possibilidades de autocuidado, como a prática de exercícios físicos ou o cuidado especial que deveria ter com os pés. Percebemos, assim, que ele age como quem espera ajuda de alguém para restabelecer sua saúde e, para ele, o cuidado pode ser interpretado como 'ordens a serem obedecidas'. Esta visão de cuidado se torna explícita ao afirmar que tem que tomar a insulina, tem que comer folha [...] tem gente que passa por cima da ordem e fica passando mal (e1). Analisando sua concepção de cuidado identificamos a falta de autonomia e de participação no planejamento do seu cuidado. Estimular a autonomia "implicaria na possibilidade de reconstruir sujeitos e sentidos, e essa resignificação teria peso significativo no seu modo de viver, incluindo-se aí a luta pela satisfação de suas necessidades de forma mais ampla possível". 16:22-3

Mesmo quando ocorrem atitudes em direção a busca por autonomia estas não são estimuladas pelos profissionais, de modo a promover uma maior independência do Sr. Miguel, ainda que seja para administrar a insulina: era a maior luta pra aplicar ne mim, aí eu pedi para o rapaz me ensinar como é que aplicava essa injeção (e1). Ao pensarmos na integralidade da atenção e em como esta deve vir materializada em práticas cuidativas, questionamos: "é possível considerar a escolha do usuário na redefinição das ações de saúde? Partindo desta questão desafiadora, pensamos que não somente é possível como amplamente necessário e desejável. Se pensarmos no cuidado em saúde como prática não normativa, mas inter-relação e intersubjetividade, a questão que se coloca é se seria possível não considerar a escolha dos usuários na definição das ações de saúde". 17:143

Colocamos, pois, em questão a prática da educação em saúde, que, pela nossa observação nos serviços de saúde buscados pelo Sr. Miguel, tem sido realizada basicamente através das reuniões do grupo de usuários diabéticos, estruturadas como aulas. Aí ela fica dando aquela lição para nós. A doutora que fica ensinando para nós como é que é para fazer. Aí nós vamos acompanhando ela (e1).

Os projetos educativos em saúde permanecem, majoritariamente, inscritos na perspectiva de transmissão de um conhecimento especializado a ser ensinado para a população cujo saber-viver é desvalorizado e/ou ignorado nesses processos de transmissão. Nessa perspectiva os profissionais de saúde assumem "[...] que, para 'aprender o que nós sabemos', deve-se desaprender grande parte do aprendido no cotidiano da vida" ${ }^{17: 1336}$ Reforça-se, dessa forma, a culpabilização da pessoa doente pela sua doença advinda de sua fraqueza moral para seguir os preceitos médicos ou da desinformação sobre o modo de viver saudável.

\section{Negação da condição crônica}

Identificamos ainda nas narrativas do $\mathrm{Sr}$. Miguel a negação de sua condição o que, talvez, justifique em parte a sua concepção do cuidado como algo externo a ele, que vem de um profissional, geralmente o médico, ou de um procedimento diagnóstico ou terapêutico. É como se a doença, embora estando em seu corpo, não lhe pertencesse, pois como afirma não sei por que eu sou diabético [...] não sei como é. [...] É um problema, né? Que tem muitas coisas que a gente quer fazer, mas não pode fazer por causa do... por causa da diabetes .... É por causa disso que a gente não pode fazer isso, muitas coisas, né (e1). Enesse processo de construção do seu saber sobre a sua doença encontra vazios explicativos para que possa articular, de maneira adequada, o tratamento e o controle como formas plausíveis de, se não evitar, pelo menos minimizar as complicações decorrentes desse agravo em seu corpo e em sua vida. ${ }^{10}$ 
Nas narrativas obtidas é possível perceber ainda que o diabetes tornou-se mais do que uma doença, se constituindo em algo que está, aos poucos, afastando-o do convívio com os amigos: tem gente que fala vamos fazer um churrasco, aí vai lá e me convida. Eaíeu nãovou (e1). Aceita-lo com todas as restrições que impõe passa a ser muito difícil, mesmo quando se convive há muitos anos com a doença, pois exige mudança na rotina, nos hábitos, a renúncia de alguns prazeres simples, mas tão necessários, como a preservação dos hábitos alimentares característicos de sua cultura nordestina, tão importante para ele. O pesar é percebido no choro e na entonação de voz, ao expressar que: é, a farinha eu não posso comer. Era o que eu mais gostava, né? [...] tô virando quase tipo indio, porque eu num posso comer sal, né (e1).

Percebemos, também, que o Sr. Miguel ainda não sente, de fato, a necessidade dessas mudanças na alimentação como parte importante para o controle do DM. A dificuldade de aceitar, de lidar e de conviver com essa condição crônica de modo permanente nos leva a pensar em um sentimento de entrega à doença, reforçado pela falta de autonomia, muitas vezes, condicionada pelas práticas profissionais. No entanto, não podemos desconsiderar que "a pessoa em condição crônica passa a conviver com ela e é esperado que busque aceitá-la. E isso não é fácil, pois a doença, de uma forma ou de outra, representa uma ameaça à vida e ao bem-estar. Aprender a aceitar a doença muitas vezes significa aceitar o que está dado, o que é limitado e doloroso, mas nosso lado humano consiste em manter sempre aberto o futuro e admitir novas possibilidades" ${ }^{\text {6:162 }}$

\section{CONSIDERAÇÕES FINAIS}

Ao mostrarmos algumas dimensões de uma pessoa que vivencia a condição crônica do DM, pudemos apreender que a doença não se instala apenas no corpo, mas ocupa um grande espaço na vida da pessoa, modificando-a em muitos aspectos. A permanência no tempo, mais ou menos prolongada, que caracteriza a condição crônica e o modo como ocorrem os arranjos nessa nova situação de vida que se apresenta a partir dela é outro fator decisivo para pensarmos a experiência de adoecimento como uma vivência única e pessoal, exigindo, portanto, por parte dos profissionais de saúde práticas de cuidado pessoalizadas.

Com base nessa percepção do evento do adoecimento como único e subjetivo, damos destaque às potencialidades que o desenho do Itinerário Terapêutico tem para nos permitir compreender como se dá a busca por cuidados empreendida por uma pessoa em condição crônica por DM e a lógica que a direciona nessa busca, tornando possível visualizar também como estão disponibilizados os serviços de saúde e as práticas de cuidado para essa condição em uma dada realidade. Assim, não é possível conceber práticas profissionais que desconsiderem a experiência de vida e, dentro dela, a de adoecimento, de cada pessoa a ser cuidada.

É, portanto, imprescindível que o profissional de saúde compartilhe saberes e decisões com a pessoa cuidada, sob risco de prescrever determinações de como andar a vida que não encontrem eco na experiência do outro. Entendemos que a integralidade da atenção voltada à pessoa que experiencia a condição crônica por DM precisa ser posta em movimento pelos profissionais de saúde em suas práticas de cuidado com base nesses pressupostos, pois dela depende a possibilidade de um enfrentamento menos sofrido dessa experiência e do abrir-se para outras formas de viver a vida.

\section{REFERÊNCIA}

1. Ministério da Saúde (BR), Secretaria de Políticas Públicas. Plano de Reorganização da Atenção à Hipertensão Arterial e ao Diabetes mellitus. Rev Saúde Pública. 2001 Dez; 35(6):585-8.

2. Organização Pan-Americana de Saúde. Doenças crônicas-degenerativas e obesidade: estratégia mundial sobre alimentação saudável, atividade física e saúde. Brasília (DF): Organização Pan-Americana da Saúde; 2003.

3. Ministério da Saúde (BR), Secretaria de Atenção à Saúde. Hiperdia [pagina na Internet]. Brasília (DF): MS; 2007 [acesso em 2007 Jun 05]. Disponível em: http://portal.saude.sp.gov.br/ resources/gestor/acesso_rapido/auditoria/ manualHIPERDIA1.5_M_02.pdf

4. Organização Mundial de Saúde. Cuidados inovadores para as condições crônicas: componentes estruturais para ação: relatório mundial. Brasília (DF): OMS; 2003.

5. Souza SPS. A repercussão da febre reumática e da cardiopatia reumática na vida de crianças e de adolescentes entre sentir-se saudável e sentir-se doente [tese]. Ribeirão Preto (SP): Universidade de São Paulo. Programa de Pós-Graduação em Enfermagem; 2006.

6. Souza SPS, Lima RAG. Condição crônica e normalidade: rumo ao movimento que amplia a potência de ser feliz. Rev Latino-am de Enfermagem. 2007 Jan-Fev; 15(1):156-64.

7. Bellato R, Araújo LFS, Castro P. O itinerário terapêutico como uma tecnologia avaliativa da 
integralidade em saúde. In: Pinheiro R, Silva Júnior AG, Mattos RA, organizadores. Atenção básica e integralidade: contribuições para estudos de práticas avaliativas em saúde. Rio de Janeiro (RJ): CEPESC, IMS/UERJ, ABRASCO; 2008.

8. Ministério da Saúde (BR), Secretaria de Atenção à Saúde, Departamento de Atenção Básica. Monitoramento na atenção básica de saúde: roteiros para reflexão e ação. Brasília (DF): Ministério da Saúde; 2004.

9. Bellato R, Araújo LFS, Faria APS, Santos EJF, Castro P, Souza SPS, et al. A História de Vida Focal e suas potencialidades na pesquisa em saúde e em enfermagem. Rev Eletr Enferm [online]. 2008 [acesso em 2009 Jan 02]; 10(3). Disponível em: http:/ / www. fen.ufg.br/revista/v10/n3/pdf/v10n3a32.pdf

10. Faria APS. A experiência de adoecimento e a busca por cuidado empreendida pela pessoa com diabetes mellitus [dissertação]. Cuiabá (MT): Universidade Federal do Mato Grosso. Programa de PósGraduação em Enfermagem; 2007.

11. Gastaldo D. É a educação em saúde "saudável"? Repensando e educação em saúde através do conceito de bio-poder. Rev Educação Realidade. 1997 Jan-Jun; 22(1):147-68.

12. Cecilio LCO. As necessidades de Saúde como Conceito estruturante na luta pela Integralidade e Eqüidade na Atenção em Saúde. In: Pinheiro R, Mattos RA, organizadores. Os sentidos da integralidade na atenção e no cuidado à saúde. $4^{a}$ ed. Rio de Janeiro (RJ): IMS/UERJ, CEPESC, ABRASCO; 2006.

13. Pinheiro R, Guizardi FL, Machado FRS, Gomes RD. Demanda em saúde e direito à saúde: liberdade ou necessidade? Algumas considerações sobre os nexos constituintes das práticas de integralidade. In: Pinheiro R, Mattos RA, organizadores. Construção social da demanda. Rio de Janeiro (RJ): IMS/UERJ, CEPESC, ABRASCO; 2005.

14. Costa AM. Integralidade na atenção e no cuidado a saúde. Saúde Soc. 2004 Set-Dez; 13(3):5-15.

15. Mattos RA. Direito, necessidades de saúde e integralidade. In: Pinheiro R, Mattos RA, organizadores. Construção social da demanda. Rio de Janeiro (RJ): IMS/UERJ, CEPESC, ABRASCO; 2005.

16. Gerhardt TE, Riquinho DL, Rotoli A. Práticas terapêuticas e apoio social: implicações das dimensões subjetivas dos determinantes sociais no cuidado em saúde. In: Pinheiro R, Mattos RA, organizadores. Cuidar do cuidado: responsabilidade com a integralidade das aç̃es de saúde. Rio de Janeiro (RJ): CEPESC, IMS/UERJ, ABRASCO; 2008.

17. Meyer DEE, Mello DF, Valadão MM, Ayres JRCM. "Você aprende. A gente ensina?" Interrogando relações entre educação e saúde desde a perspectiva da vulnerabilidade. Cad Saúde Pública. 2006 Jun; 22(6):1335-42.
Correspondência: Roseney Bellato

Av. Anita Garibaldi, Rua B, 85

78075-190 - Jardim Universitário, Cuiabá, MT, Brasil

E-mail: roseney@terra.com.br
Recebido em: 16 de junho de 2008

Aprovação final: 5 de janeiro de 2009 